\title{
Presentism, Passage, Phenomenology and Physicalism
}

\author{
Kristie Miller ${ }^{1}$ and Jane Weiling Loo ${ }^{1}$ \\ ${ }^{1}$ University of Sydney \\ Department of Philosophy \\ Sydney, New South Wales \\ Australia \\ donald.baxter@uconn.edu
}

Article info

CDD: 142.7

Received: 13.11.2016; Accepted: 17.11.2016

DOI: http://dx.doi.org/10.1590/0100-6045.2016.V39N4.KJ

Keywords:

Presentism

Passage

Physicalism

Phenomenology

\begin{abstract}
Temporal dynamists argue that we should believe that there exists temporal passage because there being passage is the best explanation for the presence of our temporal phenomenology. Presentists argue that presentism is the best (and perhaps only coherent) version of temporal dynamism. Therefore, conditional on us accepting temporal dynamism, we should accept presentism. In this paper it is argued that if we understand temporal passage as the presentist does, such an argument can succeed only if dualism is true. Thus, we conclude, either presentists should embrace dualism, or they should reject any argument for presentism that proceeds via any such argument for temporal passage that proceeds via considerations of what best explains our temporal phenomenology
\end{abstract}

\section{Introduction}

In the metaphysics of time there are arguments that proceed from various purported aspects of our phenomenology to certain metaphysical conclusions. The argument from temporal phenomenology proceeds as follows:

Manuscrito - Rev. Int. Fil. Campinas, v. 39, n. 4, pp. 183- 201, out.-dez. 2016. 
Argument from Temporal Phenomenology

(a) We have experiences as of the passage of time.

(b) If we have experiences as of the passage of time, then any reasonable explanation for this relies on the passage of time being an objective feature of reality.

Therefore:

(C): The passage of time is an objective feature of reality. ${ }^{1}$

Experiences as of the passage of time are experiences with certain content. They represent that the world is a certain way: namely that it is a way such that there is temporal passage. This leaves it open whether or not there is any passage that these are experiences of, and thus whether the experiences are veridical or not. The argument from temporal phenomenology attempts to reach a fairly general conclusion: namely that temporal passage is an objective feature of the world. Call those who accept that conclusion dynamists. Dynamists hold that the passage of time consists in the fact that a single moment of time is the objectively present one, and which moment that is, changes. Those who reject (C) we call non-dynamists. ${ }^{2}$

Dynamism is a broad church. There are various ways the world could be, metaphysically speaking, that are consistent with dynamism thus defined. Versions of the growing block view ${ }^{3}$ (according to which moments in time accrete to an existing static four-dimensional block) or the moving spotlight view $^{4}$ (according to which there is a moving present in an otherwise static

\footnotetext{
${ }^{1}$ Proponents of an argument of roughly this form include Bourne (2006, pp. 1516), Craig (2000, p. 138), and Williams (1951, pp. 465-466).

2 There are other, weaker, arguments of this kind that aim to conclude, on the basis of our temporal phenomenology, that there is prima facie reason to prefer a theory according to which there is genuine passage. Still other arguments aim to show that, on the basis of our temporal phenomenology, that there is an explanatory burden that the non-dynamist incurs, that the dynamist does not. This paper focuses on the Argument for Temporal Passage, but much of what we say will hold, mutatis mutandis, for these weaker sorts of arguments.

${ }^{3}$ Defenders of the growing block view include Broad (1923), Tooley (1997) and Forrest $(2004,2006)$.

${ }^{4}$ Cameron (2015) defends a version of this view.
}

Manuscrito - Rev. Int. Fil. Campinas, v. 39, n. 4, pp. 183- 201, out.-dez. 2016. 
four-dimensional block) or the dropping branches view ${ }^{5}$ (according to which future possible branches are real, and 'drop' as a single moment becomes the single objectively present one) all count as dynamical. But these will not be our focus. ${ }^{6}$ Our focus will be on what is arguably the most popular dynamical view: presentism. ${ }^{7}$

Presentism is the view that only present objects, property instantiations, and events exist. Presentism is a popular version of the dynamical theory because it is immune to McTaggart style arguments that attempt to show that if objects/events change from being future, to being present, to being past, then either some incoherence ensues, since the very same object/event must have all three designations, or there must be some vicious regress whereby we relativise the having of those designations to further designations of being past, present or future. ${ }^{8}$ Since for presentist only the present exists, she need not admit the designations of past or future, and certainly need to say that any set of events or objects that exist have those designations.

Second, presentism is immune to certain epistemological worries that beleaguer other dynamical theories. Dynamical theories suppose that there is an objectively present moment, and that which moment that is, changes. Any dynamical theory that admits the existence of non-present moments is, then, faced with the difficulty that which moment is objectively present can come apart from which moment is indexically present. That raises the sceptical worry that it seems as though we do not know, or cannot be justified in believing, that we are in the objectively present moment rather than merely the indexically present moment. ${ }^{9}$ Non-dynamical theories reject the claim that there is a metaphysically privileged present, holding instead that there is only an indexical notion of presentness (and thus we can be quite sure that when we believe we are in it, we are). Presentism, amongst the all the dynamical theories, is the only theory that is well placed to explain how we can be sure we are indeed in the objective present: because conditional on presentism being true, there is only one moment for us to be in: the objectively present

\footnotetext{
5 See Storrs McCall (1994).

${ }^{6}$ Though for discussion of these views, and their attendant notions of passage see Skow (2011), Benovsky (2012) and Miller (forthcoming).

7 See Bigelow (1996), Markosian (2004), Bourne (2006), Tallant (2012), and others.

${ }^{8}$ Mc'Taggart (1908) and Zimmerman (2011).

${ }^{9}$ See Bourne, Braddon-Mitchell etc.
}

Manuscrito - Rev. Int. Fil. Campinas, v. 39, n. 4, pp. 183-201, out.-der. 2016. 
one.

Thus the presentist can offer the following new argument from temporal phenomenology, to the conclusion that presentism is true.

\section{The New Argument from Temporal Phenomenology}

(a) We have experiences as of the passage of time.

(b) If we have experiences as of the passage of time, then any reasonable explanation for this relies on the passage of time being an objective feature of reality.

(c) Therefore, the passage of time is an objective feature of reality.

(d) Presentism is the best metaphysical theory that is consistent with the claim that the passage of time is an objective feature of reality.

(e) Therefore, if temporal passage is an objective feature of reality, then it is as described by a presentist theory.

(f) If temporal passage is as described by the presentist theory, then presentism is true.

(g) Therefore, presentism is true.

Our aim is to explicate a number of ways that the presentist can conceptualise temporal passage, and then to argue that on any of these, conditional on physicalism being true, temporal passage makes no difference to our temporal phenomenology. Thus the presentist who wishes to use the new argument from temporal phenomenology must endorse dualism; alternatively, the physicalist presentist must reject the new argument from temporal phenomenology.

To that end, this paper will focus on defending the following argument:

\section{Argument against the evidential role of presentist temporal passage}

i. For experience to provide evidence of temporal passage, it must be that the presence of temporal passage makes a difference to our temporal phenomenology (i.e. to its phenomenal character).

ii. If physicalism is true, it is not the case that presentist temporal passage, (i.e. temporal passage as understood by the presentist), makes a difference to our temporal phenomenology.

Manuscrito - Rev. Int. Fil. Campinas, v. 39, n. 4, pp. 183-201, out.-dez. 2016. 
iii. Therefore, if physicalism is true, our temporal phenomenology provides no evidence for the presence of presentist temporal passage.

The bulk of the paper lies in defending (ii), for, we think, premise (i) is plausible on its face. Before we do so, however, some clarifications are in order. We turn to those in the next section.

\section{Contentful States and Phenomenology}

There are various accounts that the presentist might offer; regarding what temporal passage consists in. But whatever passage consists in, we think, she must tell some story about how the existence of said passage connects with the content of our temporal phenomenology such that the latter is evidence for the former. In the following sections we consider, in more detail, the various ways in which the presentist might spell out what passage consists in. For now, however, we can just note that temporal passage, and the movement of presentness, might be such that it makes a qualitative difference to the way the world is, or it might not. We will say that temporal passage makes a qualitative difference if it makes an in principle observable, measurable, or experiential, difference to how things are. By contrast, temporal passage makes a non-qualitative difference if it makes no in principle observable, measurable, or experiential, difference to how things are.

Identity or haecceitistic properties are paradigmatically non-qualitative. They make a difference to how things are (with respect to identity facts) but that difference is not in principle observable or experiential. If presentist passage makes a qualitative difference to how things are, we can further ask whether or not the difference it makes is a physical one. Here, we assume that physical properties are those that are in principle observable, or detectable, or which feature somewhere in our best physical theories. Physical properties are causally efficacious properties; we detect them by their effects. This temporal passage makes a physical difference to the way things are, only if it makes a difference to the instantiation of physical properties; only if it makes a difference that is in principle detectable.

Making a physical difference is not the only way temporal passage could make a difference. Suppose one is a dualist; then one may suppose that a property that enters into the supervenience base of an experience can be a

Manuscrito - Rev. Int. Fil. Campinas, v. 39, n. 4, pp. 183-201, out.-dez. 2016. 
difference maker to the phenomenal character of that experience, even if that property is causally inefficacious and hence not physical. If temporal passage makes a qualitative difference to how things are, but not by making a physical difference, we will say that it makes a non-physical qualitative difference. Since no mere non-qualitative difference could be a physical difference, it follows that if presentist temporal passage can only make a non-qualitative or a qualitative non-physical difference, then it can make a difference to our temporal phenomenology only if physicalism is false. And that is what we will argue.

\section{Presentist Passage}

One way in which the presentist might understand temporal passage, is to suppose that in some sense, passage is intimately connected with real change, where, in turn, real change is not merely temporal variation (the obtaining of one set of properties at one time, and another at another time), as it were, change within the world, but change of the world. Presentists might model said passage by appealing to features already present in their metaphysics.

So, for instance, certain presentists posit the existence of primitive pasttensed properties of the world, to serve as truthmakers for past-tensed statements (Bigelow, 1996). Since, according to Bigelow, the present moment is that which makes propositions true, we can think of the present moment as being the time that instantiates a set of primitive past-tensed properties, and temporal passage as consisting in the accumulation of these properties. Indeed, we can think of past-tensed properties as a sort of growing set of properties that are the truthmakers for all past-tensed claims. If it was ever true that dinosaurs existed, it will always be true. Passage then consists in the growing membership of this set of primitive past-tensed world properties. Such a view looks a little like the growing block view, except that what grows is not the world, by accumulating time-slices, but the set of those properties.

On such an account of presentist passage, said passage makes a nonqualitative difference to the way the world is. Although the relevant set of properties grows, these properties are themselves non-qualitative. We can see that because for any present set of objects, events and qualitative properties, those objects, events and qualitative properties could have been present, and

Manuscrito - Rev. Int. Fil. Campinas, v. 39, n. 4, pp. 183-201, out.-dez. 2016. 
yet the past been different from what it actually was. That is, the very same set of qualitative properties could exist, such that the world that instantiates those properties instantiates different past-tensed properties from the pasttensed properties it actually instantiates. So, for instance, we can imagine that things are exactly as they actually are, but there were no dinosaurs: there are simply a bunch of 'fake fossils'. Had things been that way, the world would not instantiate the past-tensed property of having once had dinosaurs. Nevertheless, things would, for all that, have seemed exactly the same way.

If presentist passage consists in something like this, then it makes a nonqualitative difference to the way the world is. That need not be to say that it makes no difference at all. For suppose dualism is true. Then it might be that the non-qualitative properties (the primitive past-tensed properties) whose accumulation passage consists in, make a difference to our temporal phenomenology by being in the supervenience base of said phenomenology. But if that is how they make a difference, they do so only given that physicalism is false.

By contrast, if physicalism is true, then any difference to our temporal phenomenology must be via some physical difference that presentist passage makes to the world. Indeed, it is plausible that we can spell out what sorts of difference this would need to be. For it is, in turn, plausible that our temporal phenomenological states are quasi-perceptual. It is almost universally supposed that the content of perceptual states is at least in part a function of to what those states are causally connected; in particular, which states of the worlds typically cause those perceptual states. When we say that our temporal phenomenological states are quasi-perceptual, we mean that the phenomenal content of those states supervene on (or are in some other manner determined by) the content of (some of) our representational states, and, in turn, the content of those representational states is determined, at least in part, by to what those mental states are typically causally connected. That, in turn, means rejecting the idea that quasi-perceptual phenomenal content is intrinsic, which is to reject the claim that two individuals can be duplicates with respect to their quasi-perceptual representational mental states but fail

Manuscrito - Rev. Int. Fil. Campinas, v. 39, n. 4, pp. 183-201, out.-dez. 2016. 
to be duplicates with respect to their quasi-perceptual phenomenal content. ${ }^{10}$

So if physicalism is true, and if temporal passage makes a difference to our temporal phenomenology it must be because the mental state, or states, upon which our temporal phenomenology supervenes, are, in part, causally connected to temporal passage: that is why the content of that phenomenology is a content as of passage. (Notice that it does not follow from this that if there is no temporal passage, our phenomenology is not a phenomenology as of passage. We can have a phenomenology with the content as of stripy elephants even though there are no stripy elephants because (roughly) our phenomenology supervenes on a set of mental states that do bear appropriate causal connections to stripy-ness and to elephants. If some analogous story can be told in the case of temporal phenomenology then it may be that our phenomenology is as of passage, and that phenomenology is systematically illusory).

But that is not how the physicalist presentist who appeals to the argument from temporal passage supposes things to be. Indeed, if our phenomenology is as of passage, and temporal passage exists, but there fail to exist the relevant causal connections between passage and our mental states, then our phenomenology will still turn out to be illusory rather than veridical. That will be like a case in which each of us has a phenomenology as of a pink elephant and, by complete chance, on every such occasion there really is a pink elephant present, but that pink elephant is in no way connected to our phenomenology as of a pink elephant. In such a case our pink-elephant phenomenology would not be evidence for the presence of pink elephants (unless of course we knew that the phenomenology was accompanied by elephants - but then we would hardly need to appeal to the phenomenology as evidence for the elephants).

Thus if presentist passage makes a non-qualitative difference, as it would be if we modelled it by appealing to, for instance, the accumulation of primitive past-tensed properties, then it makes a difference to our temporal phenomenology only on the assumption that physicalism is false. For non-

\footnotetext{
${ }^{10}$ Not everyone accepts representationalism even in this limited form. See for instance Horgan and Tienson (2002) and Kriegal (2008) and Kriegal and Horgan (forthcoming).
}

Manuscrito - Rev. Int. Fil. Campinas, v. 39, n. 4, pp. 183-201, out.-dez. 2016. 
qualitative properties are not physical properties, and hence make no physical difference.

The same will hold true for other ways in which the presentist might model temporal passage. Consider, for instance, ersatz presentism. According to ersatz presentism (Markosian, 2004), the past exists. The difference between the past and present is that only the present moment is "concretely realised", and other times exist, but are not concretely realised: they are abstract ersatz times. These ersatz times are composed of propositions that provide a complete description of what is true at a particular time. Importantly, such times can be organised into an ersatz B-series (Crisp, 2007), and in this way, each time is linked by an ersatz temporal relation. The ersatz times are truthmakers for past tensed statements. One version of presentism might allow that all ersatz times that ever will exist do, tenselessly exist. On such a view it would be natural to model temporal passage in terms of the movement of presentness through these ersatz times, where the movement of presentness would consist in the changing of which ersatz time is concretely realised. Such a view would look a lot like the moving spotlight view, except that rather than the spotlight ranging over a bunch of concretely realised moments, it ranges over ersatz times, and where the light shines is the one and only concretely realised moment.

Here, again, on this model of temporal passage, it is clear that temporal passage makes a non-qualitative difference to any time. It makes a difference to the way the world is, to be sure. After all, it makes a difference to which time is concretely realised, and which is not, and that is a real difference. But consider any particular time. There is no change in what exists, or what properties are instantiated, at that time. The becoming present of a time makes no qualitative difference because the properties of the moment do not change. The propositions that are true in the present are no different to those that are true when the present time is no longer present. So, here again, it seems that temporal passage makes a non-qualitative difference; thus if it makes a difference to our phenomenology that difference is non-physical. Thus if this is what temporal passage consists in, the presentist can only avail herself of the argument from temporal phenomenology if she is willing to reject physicalism.

Manuscrito - Rev. Int. Fil. Campinas, v. 39, n. 4, pp. 183-201, out.-dez. 2016. 


\section{Substantial Passage Theories}

Perhaps, then, there are other options open to the presentist. Perhaps the presentist can hold that temporal passage makes a qualitative difference. The presentist might suggest that there really is a property of presentness that a single time, the present, instantiates, and that it is in virtue of instantiating this property that our temporal phenomenology is as it is. To make this fly, of course, the presentist will need to say that presentness is a qualitative property. So, let us consider some options.

\subsection{Presentness as an intrinsic qualitative property.}

For simplicity, let us begin by supposing that presentism is the view that (a) a single three-dimensional region of space exists, simpliciter and (b) which single three-dimensional region of space, exists, simpliciter, changes. We do not expect that most presentists suppose that this is true, and we will return to the assumption shortly. Then presentism is the view that temporal passage consists in the coming into existence of a new three-dimensional slice of being, and the cessation of existence of the previous three-dimensional slice of being.

The aim is to show that given this version of presentism, temporal passage makes no difference to our temporal phenomenology. The idea is this. According to the patchwork principle of possibility, if it is possible that $\mathrm{x}$ occur intrinsically in some spatio-temporal region $\mathrm{R}$, and it is possible that $\mathrm{y}$ occur intrinsically in some spatio-temporal region $\mathrm{R}^{*}$, then it is possible that $\mathrm{x}$ and $\mathrm{y}$ occur in adjacent spatio-temporal regions. We will not defend this principle here, and clearly the dynamist could reject it.

Since according to this version of presentism it is a new three-dimensional region of space that comes into existence as time passes, it is possible to 'patch together' intrinsic duplicates of each slice that comes into (and out of) existence in the presentist world, to create a block universe world in which the B-series ordering of events is the same as the A-series ordering of events in the presentist world. Since the block universe world is a time-for-time intrinsic duplicate of every time in the presentist world, the temporal phenomenology in that world will be the same as the temporal phenomenology in the presentist world. But then temporal passage in the

Manuscrito - Rev. Int. Fil. Campinas, v. 39, n. 4, pp. 183-201, out.-dez. 2016. 
presentist world fails to make any difference to the temporal phenomenology in that world. Here is the argument:

\section{Presentist Patching Argument (PPA)}

1. Temporal passage makes a physical difference to our phenomenology only if the mental states $M_{1} \ldots M_{n}$ upon which that phenomenology supervenes, are typically appropriately casually connected to the existence of temporal passage.

2. The patchwork principle of possibility is true.

3. There exists a block universe world, $\mathrm{w}_{\mathrm{b}}$, every one of whose times is an intrinsic qualitative duplicate of a time in a presentist world, $\mathrm{w}_{\mathrm{p}}$, and such that the times in $\mathrm{w}_{\mathrm{b}}$ are ordered, via the B-series, in the same order as those in $\mathrm{w}_{\mathrm{p}}$ are ordered via the A-series.

4. Since presentness is an intrinsic property, and every time in $\mathrm{w}_{\mathrm{p}}$ instantiates presentness, every time in $\mathrm{w}_{\mathrm{b}}$ instantiates presentness.

5. Since the mental states in $\mathrm{w}_{\mathrm{b}}$ are intrinsic duplicates of those in $\mathrm{w}_{\mathrm{p}}$, and since the same causal connections hold between the mental sates in $\mathrm{w}_{\mathrm{b}}$ as between the duplicate mental states in $\mathrm{w}_{\mathrm{p}}$, the mental states in $\mathrm{w}_{\mathrm{b}}$ have the same content as the mental states in $\mathrm{w}_{\mathrm{p}}$.

6. Therefore the content of phenomenal states in $\mathrm{w}_{\mathrm{b}}$ is the same as the content of phenomenal states in $\mathrm{w}_{\mathrm{p}}$.

7. There is no temporal passage in $\mathrm{w}_{\mathrm{b}}$.

8. Therefore, if the phenomenology in $\mathrm{w}_{\mathrm{b}}$ is as of passage, then it is illusory, and if the phenomenology is veridical then the phenomenology in $\mathrm{w}_{\mathrm{b}}$ is not as of passage.

9. Therefore, since the phenomenology in $\mathrm{w}_{\mathrm{p}}$ is the same as that in $\mathrm{w}_{\mathrm{b}}$, and since the causal connections between the mental states and the world in $\mathrm{w}_{\mathrm{p}}$ are the same as those in $\mathrm{w}_{\mathrm{b}}$, then either the phenomenology in $\mathrm{w}_{\mathrm{p}}$ is as of passage, and is illusory, or the phenomenology is not as of passage.

10. But if the phenomenology in $w_{p}$ is either illusory, or is not a phenomenology as of passage, then the presence of passage makes no physical difference to that phenomenology.

Assuming for a moment that one accepts the premises to this argument,

Manuscrito - Rev. Int. Fil. Campinas, v. 39, n. 4, pp. 183- 201, out.dez. 2016. 
it shows that this kind of presentist passage makes no physical difference to our temporal phenomenology. So if it makes any difference, it must be a nonphysical difference. Thus, if one accepts the PPA, one should conclude that the argument from temporal phenomenology is a good one only if physicalism is false.

In what follows, we defend the PPA. There are two obvious places where one might resist the argument. Both lie in the supposition that $\mathrm{w}_{\mathrm{b}}$ is possible. First, one might be a necessitarian and suppose that presentism, if true, is true of necessity. But then $\mathrm{w}_{\mathrm{b}}$ is not possible. We assume that when the presentist says that presentism is true of necessity, she means that any world that contains temporal relations is a presentist world. But then we can re-cast the argument. Suppose that $\mathrm{w}_{\mathrm{b}}$ is a four-dimensional world in which we patch together each of the three-dimensional slices in the presentist world. Now grant that those slices are not related by B-relations: instead, there exist merely geometrical and topological relations between them such that those geometrical and topological relations 'mirror' the B-relations in the presentist world. The fourth dimension in this world is not time (because this is a static block world, and such worlds do not contain time). Nevertheless it is a world with four dimensions, one of which has features that are somewhat different to those of the other three. We can think of the relation that obtains between the three-dimensional objects that are arrayed along this fourth dimension as being time-like, since they have many of the features that the non-dynamist supposes to be characteristic of actual time. Premise (3) can then be recast as $\left(3^{*}\right)$ :

(3*) There exists a 'block' universe world, $w_{b}$, every one of whose three-dimensional time-like objects is an intrinsic qualitative duplicate of a time in a presentist world, $\mathrm{w}_{\mathrm{p}}$, and such that the time-like objects in $\mathrm{w}_{\mathrm{b}}$ are ordered, topologically, along a time-like dimension in the same order as those in $\mathrm{w}_{\mathrm{p}}$ are ordered via the A-series.

One might now worry that premises (5) and (9) are false. Both appeal to the presence of causal connections between events in $\mathrm{w}_{\mathrm{b}}$. The assumption is that the same causal connections between events in $\mathrm{w}_{\mathrm{p}}$, is preserved in $\mathrm{w}_{\mathrm{b}}$. But if time is necessary for causation and there is no time in $w_{b}$, then there is no causation either. Even if we grant that time is necessary for causation, it seems reasonable to suppose that as long as the time-like dimension in $\mathrm{w}_{\mathrm{b}}$ is

Manuscrito - Rev. Int. Fil. Campinas, v. 39, n. 4, pp. 183-201, out.-dez. 2016. 
playing enough of the time-like roles of time, then there is some relation we could call causation* that obtains between events in $\mathrm{w}_{\mathrm{b}}$. The causal* relations will mirror the causal relations in $\mathrm{w}_{\mathrm{p}}$. Indeed, causal* relations in $\mathrm{w}_{\mathrm{b}}$ will be just be like what block universe theorists think actual causal relations are like. Those relations will support robust counterfactual conditionals of the sort thought to be (at least in part) definitive of causation. So although there is no space fully to defend the claim that causation* is sufficiently like causation such that the mental states in $\mathrm{w}_{\mathrm{b}}$ have the same representational content as those in $\mathrm{w}_{\mathrm{p}}$, we think it plausible that they do.

The second worry is that $\mathrm{w}_{\mathrm{b}}$ is impossible because the appeal to the patching principle is illicit. We began with the supposition that the presentist holds that passage consists in the coming into (and out of) existence of numerically distinct regions of three-dimensional space. That is what licensed our use of the patching principle. But presentists typically hold that there exists a single three-dimensional region, $\mathrm{R}$, and temporal passage consists in that region changing its properties. Then $\mathrm{w}_{\mathrm{p}}$ is a world in which the very same piece of space exists at different times, but is different at these times.

So let us consider a Newtonian block world. This is a world in which space and time are absolute. More particularly, spatial points persist (i.e. endure) through time, so that the very same space exists at different times. ${ }^{11}$ Then a Newtonian block world is, in effect, a world in which we have patched together the piece of space as it is at one time in $\mathrm{w}_{\mathrm{p}}$, with the very same piece of space as it is at some other time in $\mathrm{w}_{\mathrm{p}}$, and so on for every time in $\mathrm{w}_{\mathrm{p}}$. Newtonian block worlds occur when spatial regions are multiply located at different times. If there are possible Newtonian block worlds, then it is possible to patch together what exists at each moment in $\mathrm{w}_{\mathrm{p}}$ into a block universe such as $\mathrm{w}_{\mathrm{b}}$. We have not illicitly used the patching principle.

Of course, the necessitarian presentist will deny that $w_{b}$, thought of as a Newtonian block world, is possible. She might contend that since time

11 This is why it is possible to measure absolute motion: absolute motion is motion relative to absolute space. Something is at absolute rest through duration $\mathrm{T}$, if it is at the same place - the same bit of absolute space, throughout T. Something is in absolute motion if its absolute location at one time, is different to its absolute location at some other time.

Manuscrito - Rev. Int. Fil. Campinas, v. 39, n. 4, pp. 183-201, out.-dez. 2016. 
consists in the changing of a single moment, there is 'nowhen' in the Newtonian block world into which to 'paste' the duplicate slices. That is, wb is really a world with four spatial dimensions and no temporal dimension, with the duplicated slices from the presentist world being arraigned along this fourth spatial dimension. But we should all agree that there exists a possible world that looks very much like the Newtonian block world: the presentist wants to redescribe the fourth dimension as non-temporal. Suppose we admit that it is. Then we can offer the same response to the necessitarian that we offered previously: we can still say that the fourth dimension is time-like in various ways, and that these time-like features are such that causation* is supposed, and that, in turn, is enough for the argument to succeed.

That exhausts the plausible theories of passage according to which presentness is an intrinsic qualitative property. So far we have no found a view according to which temporal passage makes a physical difference to our temporal phenomenology. In what follows, we consider theories according to which presentness is an extrinsic property.

\section{Extrinsic Presentness}

The view that presentness is an extrinsic property is motivated by the thought that part of what makes a particular moment the present one has something to do with what is going on, or not going on, at other moments. So one might think that a crucial feature of presentism is not simply that the present moment instantiates presentness, but, rather, that what it is for it to instantiate presentness is for earlier and later moments to fail to exist.

Here, we think, the presentist might endorse a sort of present-friendly version of a view more normally defended by, inter alia, some growing block theorists. According to such views, when a moment comes into existence it instantiates presentness, and the qualitative features of that moment change when it goes from being present, to being objectively past. One example of this is known as the dead past hypothesis. Forrest $(2004 ; 2006)$ for instance, holds that what sets the objective present apart from the objective past is the presence of incomplete causal processes in the objective present. That something is an incomplete causal process is an extrinsic matter: it depends on the existence of causes that lack effects. Further, there are qualitative

Manuscrito - Rev. Int. Fil. Campinas, v. 39, n. 4, pp. 183- 201, out.-dez. 2016. 
properties that supervene only on incomplete causal processes: according to Forrest, phenomenal states are like this. Thus the instantiation of presentness, at a time, makes a qualitative difference to that time, since when $t$ instantiates presentness there exist, at $t$, persons who have phenomenal states, and when $t$ ceases to instantiate presentness there exist, at $t$, no persons who have phenomenal states.

The presentist might say something similar. According to such a view, the present moment has the qualities it does in virtue of the fact that no future (and perhaps past) moments exist. To see the difference between this view and the presentist views we already considered, let us revisit the patching argument. Suppose we patch together a block universe world in which we duplicate all of the intrinsic properties of each moment in the presentist world. If presentness is an extrinsic property, as the current view says, then we have failed to duplicate presentness. Our block universe is not a momentby-moment qualitative duplicate of our presentist world: the patching argument fails.

The presence of presentness does seem to make a physical difference to the world. But now, it if makes a physical difference then we can notice that any empirical evidence we could in principle gather will be consistent with our world being a block universe world with no temporal passage, or a world with phenomenal difference making passage. Causes are the bearers of information about the time at which they occur. According to phenomenal difference-making accounts of passage, events are causally efficacious only when they are in the objective present. So it follows that when we receive information about some non-present time, we receive information about how that time is, when it is present. So even under the assumption that non-present times exist, it is, in principle, impossible to compare what a time is like, when it is present, with what a time is like, when it is past (or future).

Moreover, we know, a priori, that we can develop a full (and accurate) scientific explanation for our temporal phenomenology. That is, we can provide a detailed mechanistic account both of what contentful mental states our phenomenal states supervene on (and what brain states those mental states supervene on) and what causal relations those mental states typically enter into (both proximally and distally). We know this is at least in principle possible, since according to phenomenal difference-making views, presentness makes a causal difference, and so it is the kind of thing that can

Manuscrito - Rev. Int. Fil. Campinas, v. 39, n. 4, pp. 183-201, out.-dez. 2016. 
(and eventually will) enter into our scientific explanations. Call this, a mechanistic explanation ME.

Suppose the presentist takes extrinsic presentness to supervene on the intrinsic and extrinsic properties of the time that instantiates it. The presentist, too, will accept ME. The only difference is that the presentist will claim that, in addition to all the properties cited in $\mathrm{ME}$, there is some further, extrinsic property that is important in explaining the content of our temporal phenomenology. But now the problem is that we have no independent reason to suppose there are such properties. These are qualitative properties: they make a difference to how a time is, that instantiates them, but either those properties are already included in ME, or they are qualitative but non-physical. If the latter is the case, then we are back to where we started: the presentist must reject physicalism if she is to hold onto the argument from temporal phenomenology. Yet if these properties are physical, we ought to be able to detect them. Yet it seems impossible to imagine that we could. For how could we ever gain access to an extrinsic property whose supervenience base is the non-existence of some other time, or the non-existence of certain objects or events?

\section{Conclusion}

In this paper we hope to have showed that although presentists, as the paradigm exemplars of the temporal dynamist, can appeal to the argument from temporal phenomenology as a way to argue for presentism, they can do so only if they are prepared to jettison physicalism. We think this is a substantial cost, and therefore conclude that presentists should simply reject any such argument. But not everyone finds physicalism so plausible. So we simply offer a conditional conclusion: insofar as one takes physicalism to be plausible, and one wishes to defend presentism, one ought not do so by mounting the argument from temporal phenomenology.

Manuscrito - Rev. Int. Fil. Campinas, v. 39, n. 4, pp. 183-201, out.-dez. 2016. 


\section{References}

BARON, S. (forthcoming). "Feel the Flow" Synthese.

Bigelow, J. "Presentism and properties". Philosophical Perspectives 10 (Metaphysics):35-52, 1996.

Bourne, C. A Future for Presentism. Oxford, Oxford, 2006.

BROAD, C. D. Scientific Thought. Routledge and Kegan Paul, 1923.

ButTERFIELD, J. The Arguments of Time. OUP, 2006.

CALLEnder, C. “Time's ontic voltage." In The Future of the Philosophy of Time (A. Bardon, ed.), 73-98, Routledge, London, 2011.

CAMERON, R. The Moving Spotlight: an essay on time and ontology. OUP, 2015.

Chalmers, D. The Conscious Mind. OUP, 1996.

Craig, W. L. The Tensed Theory of Time: A Critical Examination. Kluwer Academic Publishers, Dordrecht, 2000.

CRISP, T. M. "Presentism and the grounding objection." Noûs (41): 90-109, 2007.

DAInTON, B. "Time, passage, and immediate experience." In The Oxford Handbook of Philosophy of Time (A. Bardon, ed.), 381-418, Oxford University Press, Oxford, 2011.

FORREST, P. "The read but deal past: A reply to Braddon-Mitchell" Analysis 65 (4): 358-362, 2004.

"Uniform Grounding of Truth and the Growing Block Theory: A Reply to Heathwood." Analysis 66 (290): 161-162, 2006.

Hoerl, C. "Do we (seem to) perceive passage?" Philosophical Explorations, 17, 188-202, 2014.

Horgan, T. and TIENSON, J. "The Intentionality of Phenomenology and the Phenomenology of Intentionality," in D. Chalmers, Philosophy of Mind: Classical and Contemporary Readings, Oxford: Oxford University Press, 520-933, 2002.

Manuscrito - Rev. Int. Fil. Campinas, v. 39, n. 4, pp. 183-201, out.-dez. 2016. 
KRIEGEL, U. “Real Narrow Content,” Mind and Language, (23): 305-328, 2008. and Horgan T. forthcoming, "The Phenomenal Intentionality Research Program," in Terry Horgan and Uriah Kriegel (eds.), Phenomenal Intentionality: New Essays, Oxford: Oxford University Press.

LEININGER, L. "Presentism and the Myth of Passage". Australasian Journal of Philosophy 93 (4):724-739, 2015.

MCTAgGarT, J. E. “The unreality of time”. Mind 17 (68):457-474, 1908.

MAudlin, T. "Remarks on the passing of time." Proceedings of the Aristotelian Society (102): 237-252, 2002. The Metaphysics Within Physics. Oxford University, Oxford, 2007.

Markosian, N. "A Defence of Presentism". Oxford Studies in Metaphysics 1 (3):47-82, 2004.

McCall, S. A Model of the Universe. Clarendon Press, 1994.

PAUL, L. A. “Temporal experience.” Journal of Philosophy (107): 333-359, 2010.

PoIDEVIN, R. The Images of Time. Oxford University Press, Oxford, 2007.

PRICE, H. Time's Arrow and Archimedes' Point: New Directions for the Physics of Time. Oxford University Press, New York, 1996. "The flow of time." In The Oxford Handbook of Time (Craig Callender, ed.), 276-311, Oxford University Press, Oxford, 2011.

Prosser, S. "A new problem for the A-theory of time." Philosophical Quarterly (50): 494-498, 2000.

"Could we experience the passage of time?" Ratio (20): 75-90, 2007. "Why does time seem to pass?" Philosophy and Phenomenological Research (85): 92-116, 2012. "Passage and perception." Noûs (47): 69-84, 2013.

SkOw, B. "Experience and the passage of time." Philosophical Perspectives (25): 359-387, 2011.

Manuscrito - Rev. Int. Fil. Campinas, v. 39, n. 4, pp. 183- 201, out.dez. 2016. 
TALLANT, J. “Ontological cheats might just prosper”. Analysis 69 (3):422-430, 2009.

"Still cheating, still prospering". Analysis 70 (3):502-506, $2010 \mathrm{a}$.

A Sketch of a Presentist Theory of Passage. Erkenntnis 73 (1):133140, 2010b.

"(Existence) Presentism and the A-theory." Analysis 72 (4): 673-681, 2012.

Tooley, M. Time, Tense, and Causation. Clarendon Press, 1997.

Zimmerman, D. Presentism and the space-time manifold. In Craig Callender (ed.), The Oxford Handbook of Philosophy of Time. Oxford University Press 163-246, 2011.

Manuscrito - Rev. Int. Fil. Campinas, v. 39, n. 4, pp. 183-201, out.-dez. 2016. 